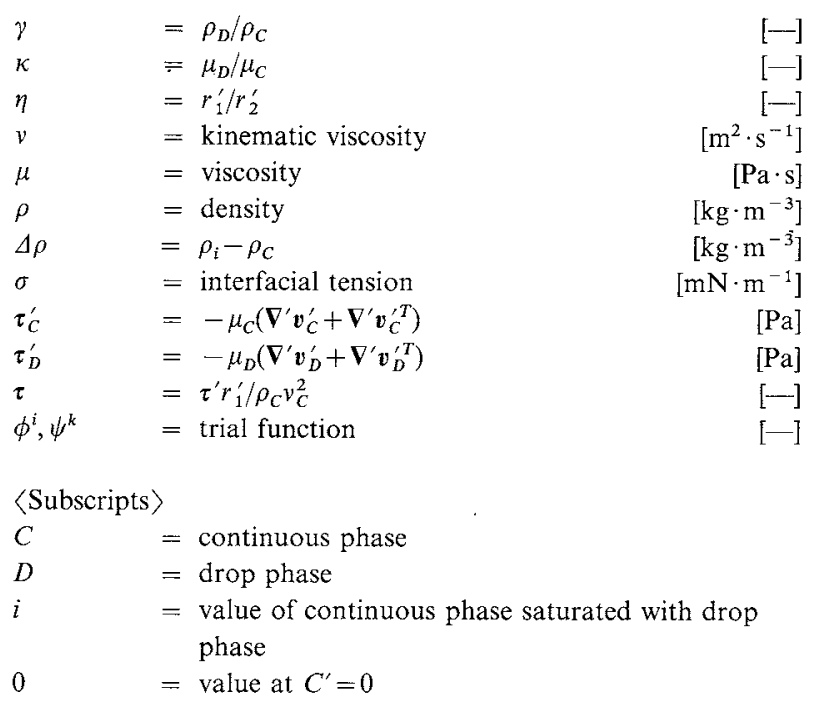

\author{
Literature Cited \\ 1) Heinrich, J. C. and O. C. Zienkiewicz: Int. J. Num. Meth. \\ Eng., 11, 1831 (1977). \\ 2) Hood, P.: Int. J. Num. Meth. Eng., 10, 379 (1976). \\ 3) Hozawa, M.: Doctoral Dissertation of Tohoku Univ., 1974. \\ 4) Hozawa, M. and T. Tadaki: J. Chem. Eng. Japan, 10, 403 \\ (1977). \\ 5) Orr, F. M. and L. E. Scriven: J. Fluid Mech., 84, 145 (1978). \\ 6) Pearson, R. S. and P. F. Dickson: AIChE J., 14, 903 (1968). \\ 7) Silliman, W. J. and L. E. Scriven: J. Comput. Phys., 34, 287 \\ (1980). \\ 8) Sitaraman, R., S. H. Ibrahim and N. R. Kuloor: J. Chem. \\ Eng. Data, 8, 198 (1963). \\ 9) Tsukada, T., M. Hozawa, N. Imaishi and K. Fujinawa: J.
Chem. Eng. Japan, 17, 246 (1984).
}

(Presented at the Third Pacific Chemical Engineering Congress, at Seoul, May 1983.)

\title{
AN EXPERIMENTAL STUDY OF MASS TRANSFER RATE IN THE DISPERSED PHASE FOR SINGLE CHARGED DROPS IN A DIELECTRIC LIOUID UNDER A UNIFORM ELECTRIC FIELD
}

\author{
MANABU YAMAGUCHI, TORU TAKAMATSU, FUMIYA YOSHIDA \\ AND TAKASHI KATAYAMA \\ Department of Chemical Engineering, Faculty of Engineering Science, \\ Osaka University, Toyonaka 560
}

Key Words: Charged Drops, Drop Formation, Liquid Extraction, Mass Transfer, Uniform Electric Field

\begin{abstract}
Mass transfer of iodine from single charged drops of aqueous iodine solution into a continuous phase of cyclohexane was measured during the overall process of formation, free fall and coalescence of the drops in a range of uniform electric field strength up to $2.4 \mathrm{kV} / \mathrm{cm}$. The total amount of iodine transferred was separated into that during drop formation and that during the subsequent stages. Each mass transfer mechanism during the formation and the free fall of drops in the electric field was investigated with theoretical and empirical equations in the literature, which were obtained in the absence of an electric field.

The mechanism of mass transfer during the formation of the charged drops in the presence of an electric field and that during free fall of the drops are the same as those obtained in the absence of an electric field. The enhancement of mass transfer obtained in the electric field is due to the increased effective interfacial area per volume of dispersed phase and to the increased moving velocity of the drops caused by applying the electric field.
\end{abstract}

\section{Introduction}

In separation processes dealing with liquid drops, various attempts have been made to enhance their mass transfer efficiencies. Generally, enhancement can be obtained by producing a larger interfacial area for diffusion and a higher degree of turbulence within and around drops for eddy diffusion. The require-

Received December 7, 1984. Correspondence concerning this article should be addressed to $\mathrm{T}$. Katayama. ment for making turbulence coupled with a larger interfacial area is difficult because these features are incompatible in the sense that small drops do not have high relative velocities, nor do they exhibit marked internal circulation patterns. The application of an electric field as a technique to overcome these problems has been proposed by Thornton and coworkers. ${ }^{2-4,21,22)}$ This technique has the following advantages. Small charged drops can be produced easily by using an electrostatic force, ${ }^{2-4,17)}$ and the 
Table 1. Physical properties of liquids used at $20^{\circ} \mathrm{C}$

\begin{tabular}{lccccc}
\hline & $\begin{array}{c}\text { Density } \\
{\left[\mathrm{kg} / \mathrm{m}^{3}\right]}\end{array}$ & $\begin{array}{c}\text { Interfacial tension } \\
{[\mathrm{mN} / \mathrm{m}]}\end{array}$ & $\begin{array}{c}\text { Viscosity } \\
{[\mathrm{mPa} \cdot \mathrm{s}]}\end{array}$ & $\begin{array}{c}\text { Dielectric constant } \\
{[-]}\end{array}$ & $\begin{array}{c}\text { Electric conductivity } \\
{[\mathrm{S} / \mathrm{m}]}\end{array}$ \\
\hline Water & 998 & - & 1.00 & 80.1 & $10^{-6}$ \\
Cyclohexane & 770 & 48.0 & 0.98 & 2.02 & $\sim 10^{-16}$ \\
\hline
\end{tabular}

Diffusivity of iodine in water is estimated as $1.22 \times 10^{-9}\left[\mathrm{~m}^{2} / \mathrm{s}\right] .^{203}$

charged drops can move through a continuous phase with higher relative velocity due to the Coulomb force, ${ }^{2,18)}$ which in consequence induces a higher degree of fluid turbulence within and around the drops. ${ }^{19)}$ Thus it is useful in mass transfer operations to produce large interfacial area coupled with enhanced transfer coefficients. Furthermore, the direct utilization of electrical energy with processes dealing with liquid drops will obtain higher energy efficiencies than energy supplied in thermal or mechanical form. Several investigators ${ }^{2-4,12,14,21,22)}$ have studied the effects of an electric field on heat and mass transfer rates in liquid-liquid systems and have suggested that it produces significant enhancement in heat and mass transfer coefficients.

Recently, Berg and co-workers ${ }^{5)}$ have investigated theoretically the transient and quasi-steady heat and mass transfer between a moving uncharged drop and its surroundings in a uniform electric field for the case of low Reynolds and high Péclet numbers. They have also developed the problem for the case of intermediate Reynolds numbrs. ${ }^{6)}$ Unfortunately, the validity of their equations has not been confirmed experimentally.

This work is an extension of our previous studies $^{17,18)}$ and its objects are as follows: 1) to measure simultaneously mass transfer rate in the dispersed phase for single charged drops and the behavior of the drops moving through a continuous liquid phase in a uniform electric field, and 2) to investigate the effect of interaction of surface charge of the drop with the electric field on the mass transfer rate, that is, the mechanism of mass transfer for each drop lifetime.

\section{Experimental}

Experiments were carried out for extraction of iodine from single charged drops of aqueous iodine solution into a continuous phase of cyclohexane for various electric field strengths. Iodine as a transfer material was used to allow the evaluation of dispersed phase-controlled mass transfer ${ }^{24)}$ because the distribution coefficient of iodine between the dispersed and continuous phases in the present experiment is 0.015 . The physical properties of liquids used are listed in Table 1.

Figure 1 shows a schematic diagram of the experi-

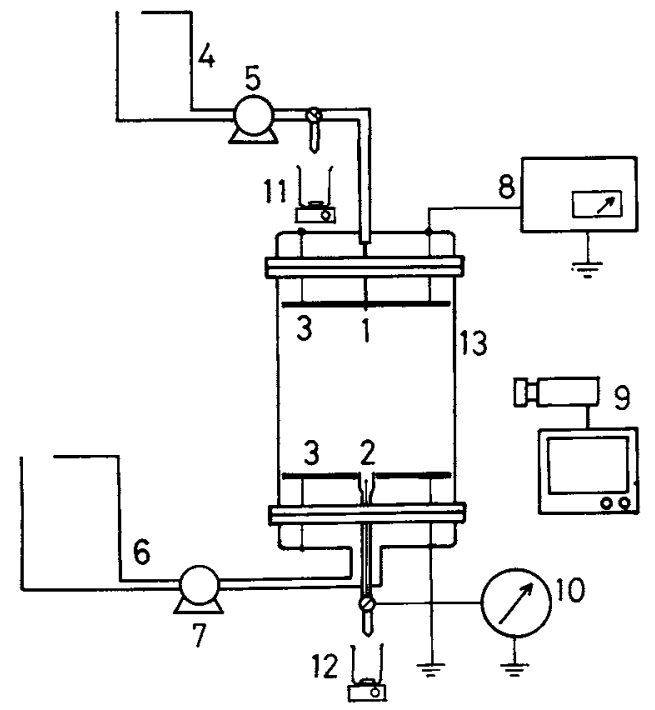

Fig. 1. Schematic diagram of experimental apparatus: 1, nozzle; 2 , drop collector; 3 , copper disk; 4 , dispersed phase reservoir; 5, micro-tube pump; 6 , continuous-phase reservoir; 7, feed pump; 8, H.V. generator; 9, T.V. system; 10 , electrometer; 11, inlet sampling beaker; 12, outlet sampling beaker; 13, glass column.

mental apparatus. A glass column (i.d. $30 \mathrm{~cm}$ ) [13] equipped with a pair of electrodes was filled with cyclohexane as the continuous phase. Upper and lower electrodes [3], made of copper disks, had a diameter of $30 \mathrm{~cm}$, the same size as the inner diameter of the column. The distance between the electrodes were $5 \mathrm{~cm}$ and $15 \mathrm{~cm}$. Each distance corresponds to the effective travelling distance for the drops. This arrangement of electrodes was determined so as to obtain a uniform electric filed. ${ }^{16,17)}$ The continuous phase of cyclohexane was supplied from a liquid reservoir [6] by a feed pump [7]. The dispersed phase of aqueous iodine solution was supplied from another liquid reservoir [4] to a stainless steel nozzle $(0.1 \mathrm{~cm}$ o.d., $0.06 \mathrm{~cm}$ i.d.) [1] by a micro-tube pump [5]. The nozzle was extended $0.1 \mathrm{~cm}$ into the electric field from the center of the upper electrode and was connected, together with the electrode, to a high-voltage generator (Brandenburg 2907P) [8]. The applied voltage for the experiments was varied from 0 to $36 \mathrm{kV}$ and the lower electrode was earthed. That is, the electric field strength (=applied voltage/electrode gap) was varied from 0 to $2.4 \mathrm{kV} / \mathrm{cm}$ at $0.8 \mathrm{kV} / \mathrm{cm}$ intervals. Single charged drops were produced at regular in- 
tervals from the nozzle. The flow rate of the dispersed phase was in a range of $0.0022-0.011 \mathrm{~cm}^{3} / \mathrm{s}$. In that range, volumes of the drops produced in each field strength were nearly equal and were independent of the frequency of drop formation. ${ }^{17)}$ After falling through a given distance, the drops were collected into a collector [2] at the center of the lower electrode.

Formation and falling times of the charged drops were recorded by a set of a telescopic camera, a videorecorder and a television monitor fitted with a digital timer. The drop volume, drop charge and terminal velocity of the drop were measured in the same way as in the previous study. ${ }^{17,18)}$ The experimental error of drop volume (or formation time of the drops) is estimated to be within $\pm 10 \%$ and that of the terminal velocity to be within $\pm 2 \%$. The total amount of iodine transferred was obtained as follows: The dispersed phase was sampled at inlet [11] and at outlet [12] of the column as initial and final concentrations of iodine, respectively. To prevent the volatilization of iodine into the atmosphere the samples were taken directly into aqueous potassium iodide solutions $[11,12]$. The concentration of iodine was analyzed by iodometry.

\section{Results and Discussion}

\subsection{Volume of charged drops and their terminal} velocities

The experimental results for the volumes $(O)$ of charged drops and their terminal velocities $(\triangle)$ are plotted against the electric field strength in Fig. 2. The solid (drop volume) and the broken (terminal velocity) lines in the figure are the values calculated by the following equations. ${ }^{16-18)}$

$$
\begin{gathered}
\pi D_{\mathrm{n}} \sigma=\phi \Delta \rho g v+4 \pi \varepsilon_{\mathrm{c}}(\alpha+0.34)\left(\frac{3 v}{4 \pi}\right)^{2 / 3} E_{0}^{2} \\
Q=4 \pi \varepsilon_{\mathrm{c}}(\alpha+0.63)\left(\frac{3 v}{4 \pi}\right)^{2 / 3} E_{0} \\
\frac{8 \Delta \rho_{\text {eff. }} g v}{\pi d_{\mathrm{e}} \sigma_{\text {eff. }}}\left(\frac{\rho_{\mathrm{c}} \sigma_{\text {eff. }}^{3}}{g \mu_{\mathrm{c}}^{4}} \cdot \frac{\rho_{\mathrm{c}}}{\Delta \rho_{\text {eff. }}}\right)^{0.15} \\
=\frac{4}{3}\left\{\frac{\rho_{\mathrm{c}} d_{\mathrm{e}} u_{\mathrm{t}}}{\mu_{\mathrm{c}}}\left(\frac{\rho_{\mathrm{c}} \sigma_{\text {eff. }}^{3}}{g \mu_{\mathrm{c}}^{4}} \cdot \frac{\rho_{\mathrm{c}}}{\Delta \rho_{\mathrm{eff} .}}\right)^{-0.15}+0.75\right\}^{1.275} \\
\Delta \rho_{\text {eff. }}=\Delta \rho+\frac{Q E_{0}}{g v} \\
\sigma_{\text {eff. }}=\sigma-\left(\frac{3}{8} d_{\mathrm{e}} \varepsilon_{\mathrm{c}} E_{0}^{2}+\frac{1}{8 \pi \varepsilon_{\mathrm{c}} d_{\mathrm{e}}} \cdot \frac{Q^{2}}{\pi d_{\mathrm{e}}^{2}}\right)
\end{gathered}
$$

The experimental drop volumes decrease markedly with increasing field strength and the solid line calculated by using Eq. (1) shows good agreement with the experimental ones. On the other hand, experimental terminal velocities increase significantly with increasing field strength, and the broken line calculated by

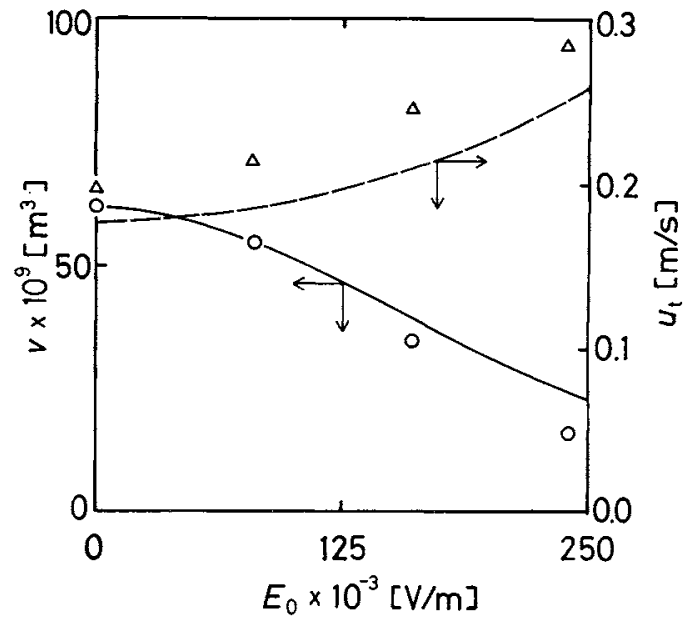

Fig. 2. Volume $(O)$ and terminal velocity $(\triangle)$ of uncharged drop or charged drop vs. electric field strength:,$- v$ vs. $E_{0}$ calculated by Eq. (1); - - - , $u_{t}$ vs. $E_{0}$ calculated by Eqs. (1), (2) and (3).

using Eqs. (1), (2) and (3) is somewhat lower than the experimental data.

In general, it is well known that as a drop becomes smaller in size it behaves like a rigid sphere and its velocity becomes slower. However, charged drops have higher terminal velocity with increasing field strength even if the drop size becomes smaller. Both results, obtained in the present experiments, are favorable factors in mass transfer operations for a system of drops in a continuous liquid phase.

\subsection{Extraction efficiency}

2.2.1 Total extraction efficiency The fractional approaches to each concentration equilibrium (extraction efficiency) during formation, free fall, and coalescence of the drops, respectively, were defined by Johnson and Hamielec ${ }^{11}$ as follows:

$$
\begin{aligned}
& F_{1}=\left(C_{0}-C_{1}\right) /\left(C_{0}-C^{*}\right) \\
& F_{2}=\left(C_{1}-C_{2}\right) /\left(C_{1}-C^{*}\right) \\
& F_{3}=\left(C_{2}-C_{3}\right) /\left(C_{2}-C^{*}\right)
\end{aligned}
$$

where the concentration in the drop for each stage is assumed to be uniform. In practice only $C_{0}$ and $C_{3}$ are directly measurable, and the corresponding efficiency is defined as the total extraction efficiency $F_{a}$, which is rearranged by using $F_{1}, F_{2}$ and $F_{3}$ as follows:

$$
\begin{aligned}
F_{\mathrm{a}} & =\left(C_{0}-C_{3}\right) /\left(C_{0}-C^{*}\right) \\
& =1-\left(1-F_{1}\right)\left(1-F_{2}\right)\left(1-F_{3}\right)
\end{aligned}
$$

Figure 3 shows the relation between total extraction efficiency $\left(F_{\mathrm{a}}^{\mathrm{I}}\right)$ and electric field strength $\left(E_{0}\right)$ with the flow rate of the dispersed phase as a parameter for the case of $5-\mathrm{cm}$ electrode gap. Each enhancement of total efficiencies against electric field strength shows a similar tendency. Therefore, each difference among 


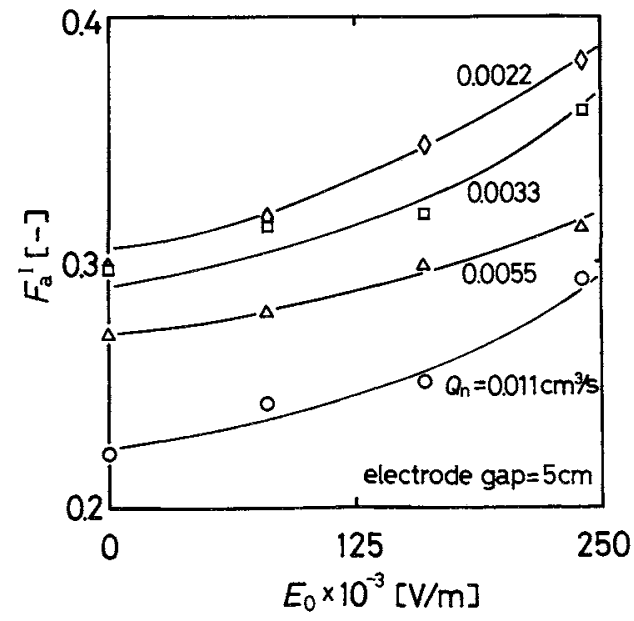

Fig. 3. Total extraction efficiency of iodine from uncharged drops or charged drops plotted against electric field strength for different flow rates of dispersed phase.

efficiencies under constant field strength corresponds to the difference of efficiencies during formation of the drops. The enhancement for each flow rate is about 30 per cent in the range of the present conditions. This is due to an increase of effective interfacial area of the dispersed phase and a higher degree of turbulence within and around the drops caused by increased relative velocity, as mentioned in the preceding section.

2.2.2 Extraction efficiency during drop formation For mass transfer rate during drop formation, various modified penetration models have been proposed. ${ }^{15)}$ In the case of low extraction efficiency, efficiency is approximately by a penetration model as follows:

$$
\begin{aligned}
F_{1} & \approx-\ln \left(1-F_{1}\right) \\
& =k \sqrt{\frac{\mathscr{D}}{\pi t_{\mathrm{f}}}} \cdot \frac{S_{\mathrm{f}}}{v} \cdot t_{\mathrm{f}}
\end{aligned}
$$

where the value of $k$ is a constant depending on the relation between the surface area and the volume of a drop being formed during one cycle of growth, and the values in the literature are summarized as follows.

$$
k=\left\{\begin{array}{l}
0.857 \text { Licht and Pansing }{ }^{13)} \\
1.31 \text { Angelo et al., }{ }^{11} \text { Ilkovic }^{10)} \\
1.48 \text { Groothius and Kramers } \\
3.43 \text { Heertjes } \text { et al. }{ }^{9)}
\end{array}\right.
$$

If it is assumed that the motion of charged drops and time of coalescence are independent of feed rate of the dispersed phase under constant field strength, the total efficiencies, in which only the drop formation time varies, may be proportional to the square root of the formation time. From Eqs. (5) and (6),

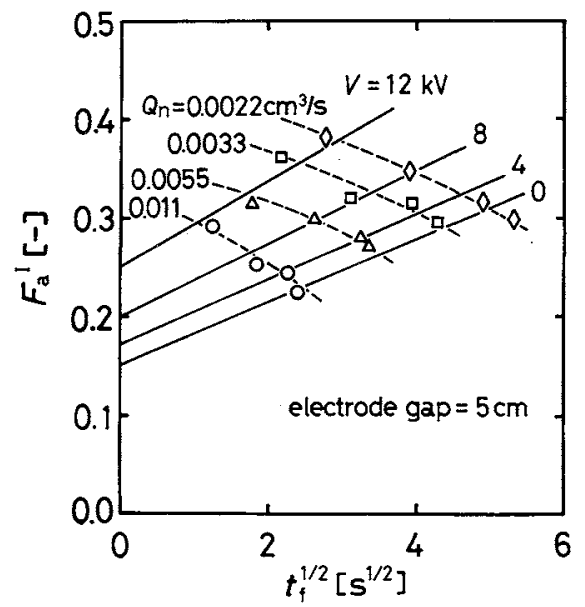

Fig. 4. Total extraction efficiency vs. square root of formation time of uncharged and charged drops.

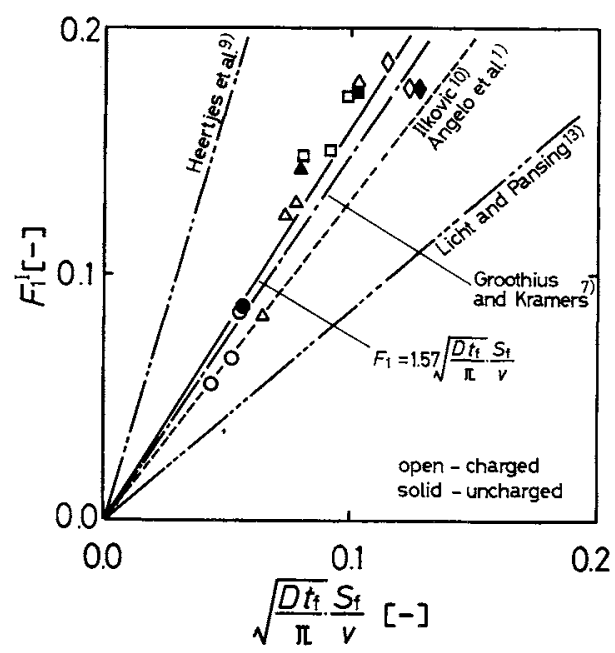

Fig. 5. Comparison of experimental with theoretical values of extraction efficiency during drop formation (keys are the same as used in Fig. 3).

$$
F_{\mathrm{a}}=a t_{\mathrm{f}}^{1 / 2}+b
$$

where

$$
\left.\begin{array}{l}
a=k \sqrt{\frac{\mathscr{D}}{\pi}} \cdot \frac{S_{\mathrm{f}}}{v}\left(1-F_{2}\right)\left(1-F_{3}\right) \\
b=1-\left(1-F_{2}\right)\left(1-F_{3}\right)
\end{array}\right\}
$$

Experimental results for the case of 5-cm electrode gap are shown in Fig. 4, in which $F_{\mathrm{a}}^{\mathrm{l}}$ is plotted against $t_{\mathrm{f}}^{1 / 2}$. The values of $a^{\mathrm{I}}$ and $b^{\mathrm{I}}$ in Eq. (8) were determined for each electric field strength by the method of least squares. The broken lines represent contours of nozzle flow rates. Although both formation and residence times of the drop under constant flow rate decrease with increase of the field strength, as was shown in Fig. 2, efficiency increases with field strength. This means that the contributions to mass transfer of increased interfacial area and of enhanced circulation within the drop would be larger than those of the 


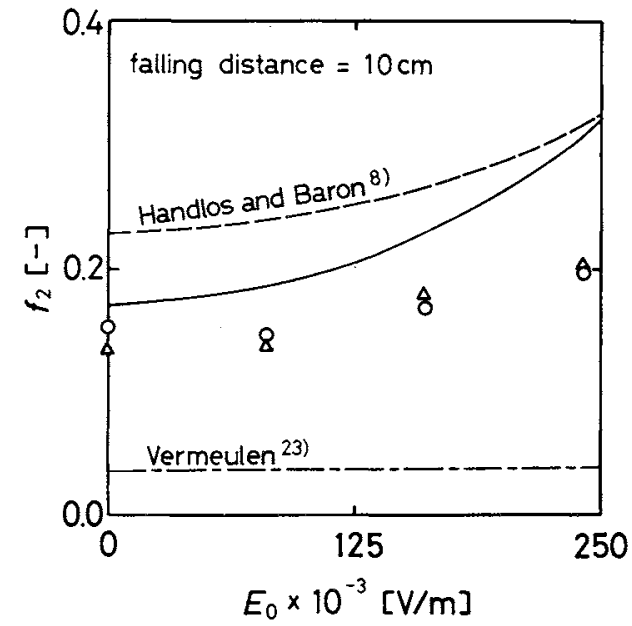

Fig. 6. Extraction efficiency during free fall of uncharged and charged drops in an electric field: $O, \triangle$, experimental (keys are the same as used in Fig. 3); _ , calculated by Eqs. (1), (2), (3), (13) and (14).

reductions in formation and residence times.

Extraction efficiency during formation of the drop, $F_{1}^{\mathrm{l}}$, is given from Eqs. (8) and (9) as

$$
F_{1}^{\mathrm{l}}=1-\frac{\left(1-F_{\mathrm{a}}^{\mathrm{I}}\right)}{\left(1-b^{\mathrm{I}}\right)}
$$

$F_{1}^{1}$ value is plotted against experimental value of $\sqrt{\mathscr{D} t_{\mathrm{f}} / \pi} \cdot S_{\mathrm{f}} / v$ in Fig. 5, where the slope of the solid line shows the value of $k$ in Eq. (6). Its value was determined to be 1.57. From the result that the efficiencies for both uncharged (solid symbols) and charged (open symbols) drops could be correlated by the line, it is considered that the mechanism of mass transfer within charged drops is the same as that within uncharged drops. This result is similar to that obtained for gas absorption rate during the formation of charged drops. ${ }^{25)}$ The value of 1.57 obtained for $k$ in the present study is close to the fresh-surface penetration model of Groothius and Kramers. ${ }^{7)}$

2.2.3 Extraction efficiency during free fall of the drops Amount of iodine transferred during free fall of the drops in the electric field was evaluated by changing the traveling distances of the drops, where drops of the same size fell through two traveling distances $(15 \mathrm{~cm}$ and $5 \mathrm{~cm})$ under the condition of constant electric field strength. When the drops fell through an effective traveling distance $(10 \mathrm{~cm})$ between $15 \mathrm{~cm}$ and $5 \mathrm{~cm}$, the extraction efficiency during free fall, $f_{2}$, was estimated from $F_{2}^{\mathrm{I}}$ and $F_{2}^{\mathrm{II}}$ by the following equation.

$$
\begin{aligned}
f_{2} & =\left(C_{2}^{\mathrm{I}}-C_{2}^{\mathrm{II}}\right) /\left(C_{2}^{\mathrm{I}}-C^{*}\right) \\
& =1-\frac{\left(1-F_{2}^{\mathrm{I}}\right)}{\left(1-F_{2}^{\mathrm{I}}\right)}
\end{aligned}
$$

$F_{3}^{1}$ and $F_{3}^{\text {Il }}$ values are assumed to be nearly equal to each other, because the charged drops unite instantaneously with the coalescing phase earthed in the collector, and $F_{1}^{\mathrm{II}}$ value is entirely the same as $F_{1}^{\mathrm{I}}$ value. The $f_{2}$ in Eq. (11) is given by using Eq. (5) as follows:

$$
f_{2}=1-\frac{\left(1-F_{\mathrm{a}}^{\mathrm{II}}\right)}{\left(1-F_{\mathrm{a}}^{\mathrm{I}}\right)}
$$

Figure 6 shows the relation between efficiency $\left(f_{2}\right)$ and electric field strength. Circular and triangular symbols in the figure show the values calculated by Eq. (12). The efficiency increases with the field strength. Yamaguchi and Katayama ${ }^{26)}$ proposed the following empirical equation for mass transfer in the dispersed phase of circulating drops in the absence of any electric field.

$$
\frac{k_{\mathrm{d}} d_{\mathrm{e}}}{\mathscr{D}}=3 \times 10^{3}\left(\frac{4 \mathscr{D} t_{\mathrm{r}}}{d_{\mathrm{e}}^{2}}\right)^{-0.5}\left(\frac{\mu_{\mathrm{d}}}{\mu_{\mathrm{c}}}\right)^{0.5} \frac{\mu_{\mathrm{c}} u_{\mathrm{t}}}{\sigma}
$$

The $f_{2}$ value is given as follows by assuming a spherical charged drop:

$$
f_{2}=k_{\mathrm{d}} \frac{S_{\mathrm{f}}}{v} t_{\mathrm{r}}=\frac{6 k_{\mathrm{d}}}{d_{\mathrm{c}}} t_{\mathrm{r}}
$$

The solid line calculated by Eqs. (1), (2), (3), (13) and (14) gives values about $20 \%$ higher than the experimental ones. This is probably because the calculated residence time of the drops is longer than the experimental value, as shown in Fig. 2. The broken line shows the calculated value based on a model of Handlos and Baron, ${ }^{8}$ who proposed a circulation model inside an uncharged drop. Their model predicts much higher values than the experimental ones. It is considered that the random motion inside the drops in the present work could not be as intensive as that given by their model. On the other hand, the dash-dotted line shows the values calculated by Vermeulen's equation $^{23)}$ for a stagnant drop. A possible explanation for the enhancement of the $f_{2}$ value with increasing field strength may be related to the results shown in Fig. 2; increased interfacial area of the drops per volume of dispersed phase supplied and the enhanced circulating motion within the drops associated with increasing terminal velocity are obtained. It is concluded that the effects of the surface charge of the drops and the applied electric field on the mechanism of mass transfer itself is substantially small.

\section{Conclusion}

An experimental investigation was carried out for mass transfer resistance in the dispersed drop and for moving behavior of single charged drops falling through a continuous liquid phase in the presence of a uniform electric field. The conclusions of the present work are summarized as follows. 
1) Enhancement of total extraction efficiency was obtained with electric field strength. This is due to the increase in effective interfacial area of the drop and the intensive circulating motion inside the drop.

2) The mass transfer mechanism during the formation of single charged drops was explained by the penetration theory of fresh-surface type and was not influenced by the presence of the electric field.

3) The mass transfer mechanism of charged drops falling in the electric field was also estimated to be similar to that of uncharged drops.

4) The application of an electric field to separation processes dealing with liquid drops has significant effects on drop size, drop velocity and phase separation of two-liquid phases. Therefore, it is useful for improving efficiencies of heat and mass transfer in liquid-liquid systems.

\section{Acknowledgment}

This work was partially supported by a Grant-in-Aid for Developmental Scientific Research from the Ministry of Education, Science and Culture of Japan. The authors are grateful to Messrs. A. Kobayashi and Y. Kagami for their assistance in the experimental work.

\section{Nomenclature}

Eqe

$C_{0} \quad=$ initial iodine concentration of a drop $\left[\mathrm{mol} / \mathrm{m}^{3}\right]$

$C_{1} \quad=$ iodine concentration of a drop just after detaching from a nozzle

$C_{2} \quad=$ iodine concentration of a drop just before landing on coalesced phase $\quad\left[\mathrm{mol} / \mathrm{m}^{3}\right]$

$C_{3} \quad=$ final iodine concentration of a drop $\quad\left[\mathrm{mol} / \mathrm{m}^{3}\right]$

$C^{*} \quad=$ iodine concentration of a drop in equilibrium with that of continuous phase $\quad\left[\mathrm{mol} / \mathrm{m}^{3}\right]$

$\mathscr{D}=$ diffusivity of iodine in water $\left[\mathrm{m}^{2} / \mathrm{s}\right]$

$D_{n} \quad=$ outer diameter of a nozzle $\quad[\mathrm{m}]$

$d_{\mathrm{c}}=$ equivalent spherical diameter of a drop $[\mathrm{m}]$

$E_{0} \quad=$ uniform electric field strength $\quad[\mathrm{V} / \mathrm{m}]$

$F_{\mathrm{a}} \quad=$ total extraction efficiency $\quad[-]$

$F_{1} \quad=$ extraction efficiency during drop formation $\quad[-]$

$F_{2} \quad=$ extraction efficiency during drop free-fall $\quad[-]$

$F_{3} \quad=$ extraction efficiency during drop coalescence $[-]$

$f_{2} \quad=$ extraction efficiency during drop free-fall between $5 \mathrm{~cm}$ and $15 \mathrm{~cm}$ distances $\quad[-]$

$=$ gravitational acceleration $\quad\left[\mathrm{m} / \mathrm{s}^{2}\right]$

$=$ coefficient in Eq. (6) [-]

$=$ mass transfer coefficient in dispersed phase $[\mathrm{m} / \mathrm{s}]$

$=$ nozzle length extended from electrode [-]

= electric charge of a drop $\quad[\mathrm{C}]$

= flow rate of dispersed phase through nozzle $\left[\mathrm{m}^{3} / \mathrm{s}\right]$

$=$ radius of a drop [m]

$=$ interfacial area of a forming drop $\quad\left[\mathrm{m}^{2}\right]$

$=$ formation time of a drop [s]

$=$ residence time of a drop in continuous phase [s]

$=$ terminal velocity of a drop $\quad[\mathrm{m} / \mathrm{s}]$

$=$ volume of a drop $\quad\left[\mathrm{m}^{3}\right]$

$=(l+r) / r \quad[-]$

$=$ permittivity $[\mathrm{F} / \mathrm{m}]$

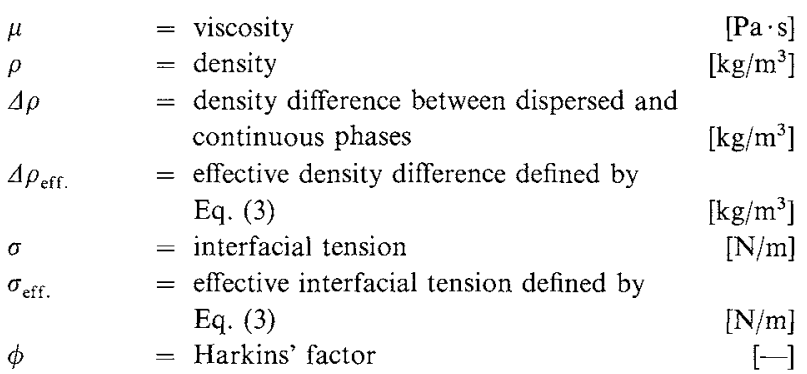

〈Subscripts〉

$\begin{array}{ll}\mathrm{c} & =\text { continuous phase } \\ \mathrm{d} & =\text { dispersed phase }\end{array}$

〈Superscripts〉

I $=$ traveling distance $(5 \mathrm{~cm})$ of a drop

II $\quad=$ traveling distance $(15 \mathrm{~cm})$ of a drop

\section{Literature Cited}

1) Angelo, J. B., E. N. Lighfoot and D. W. Howard: AIChE J., 12, 751 (1966).

2) Bailes, P. J.: Ind. Eng. Chem. Process Des. Dev., 20, 564 (1981).

3) Bailes, P. J. and J. D. Thornton: Proc. Internatl Solvent Extraction Conf., p. 1431 (1971).

4) Bailes, P. J. and J. D. Thornton: Proc. Internatl Solvent Extraction Conf., p. 1011 (1974).

5) Chang, L. S., T. E. Carleson and J. C. Berg: Int. J. Heat and Mass Transfer, 25, 1023 (1982).

6) Chang, L. S. and J. C. Berg: Int. J. Heat and Mass Transfer, 26, 823 (1983).

7) Groothius, H. and H. Kramers: Chem. Eng. Sci, 4, 17 (1955).

8) Handlos, A. E. and T. Baron: AIChE J., 3, 127 (1957).

9) Heertjes, P. M., W. A. Holve and H. Talsma: Chem. Eng. Sci., 3, $122(1954)$

10) Ilkovic, D.: Coll. Czech. Chem. Commun., 6, 489 (1934).

11) Johnson, A. I. and A. E. Hamielec: AIChE J., 6, 145 (1960).

12) Kaji, N., Y. H. Mori, Y. Tochitani and K. Komotori: Trans. ASME., J. of Heat Transfer, 102, 32 (1980).

13) Licht, W. and W. F. Pansing: Ind. Eng. Chem., 45, 1885 (1953).

14) Morrison, Jr., F. A.: Trans. ASME., J. of Heat Transfer, 99, 269 (1977).

15) Popovich, A. T., R. E. Jervis and O. Trass: Chem. Eng. Sci., 19, 357 (1964).

16) Takamatsu, T., Y. Hashimoto, M. Yamaguchi and T. Katayama: J. Chem. Eng. Japan, 14, 178 (1981).

17) Takamatsu, T., M. Yamaguchi and T. Katayama: J. Chem. Eng. Japan, 15, 349 (1983).

18) Takamatsu, T., M. Yamaguchi and T. Katayama: J. Chem. Eng. Japan, 16, 324 (1983).

19) Taylor, G.: Proc. Roy. Soc., A291, 159 (1966).

20) The Soc. Chem. Engrs Japan Ed.: "Kagaku Kogaku Benran," p. 68, Maruzen, Tokyo (1978).

21) Thornton, J. D.: Rev. Pure and Appl. Chem., 18, 197 (1968).

22) Thornton, J. D.: Birmingham Univ. Chem. Engr., 27, 6 (1976).

23) Vermeulen, T.: Ind. Eng. Chem., 45, 1664 (1953).

24) Yamaguchi, M., T. Fujimoto and T. Katayama: J. Chem. Eng. Japan, 8, 361 (1975).

25) Yamaguchi, M., Y. Hashimoto, T. Takamatsu and T. Katayama: Int. J. Heat and Mass Transfer, 25, 1631 (1982).

26) Yamaguchi, M. and T. Katayama: J. Chem. Eng. Japan, 10, 280 (1977). 